\title{
CONTRIBUIÇÕES DE SCHLEIERMACHER PARA A FILOSOFIA CLÁSSICA ALEMÃ ${ }^{1}$
}

\section{SCHLEIERMACHER'S CONTRIBUTIONS TO CLASSIC GERMAN PHILOSOPHY}

\author{
Davison Schaeffer de Oliveira \\ Pontifícia Universidade Católica de Minas Gerais
}

\begin{abstract}
RESUMO: O presente texto intenta expor as contribuições filosóficas de Schleiermacher (1768-1834) para os estudos de filosofia clássica alemã. Primeiramente, ele se dedica a uma breve discussão dos efeitos de sua filosofia em geral, assim com de sua posição no interior da filosofia clássica alemã em particular. Em seguida, ele examina a tarefa das preleções universitárias, elaboradas durante o tempo de sua docência em Berlim, a fim de determinar o núcleo do seu conceito de filosofia. Por fim, ele levanta questões hermenêuticas pertinentes à reconstrução histórico-filosófica de seu pensamento para a pesquisa atual.
\end{abstract}

Palavras-chave: idealismo; romantismo; diálogo;

\section{ABSTRACT:}

The present text aims to expose the philosophical contributions of Schleiermacher (1768-1834) to the studies of classical German philosophy. First, we will deal with a brief discussion of the effects of his philosophy in general and of his position within classical German philosophy in particular. Next, we will dedicate ourselves to the university lectures elaborated during his time of teaching in Berlin, in order to determine the nucleus of his concept of philosophy. Finally, we will raise hermeneutic questions pertinent to the historical-philosophical reconstruction of his thought for current research.

Keywords: idealism; romanticism; dialogue;

\footnotetext{
${ }^{1}$ Pesquisa financiada pelo Programa Nacional de Pós-Doutorado PNPD/CAPES da Pontifícia Universidade Católica de Minas Gerais (PUC Minas).
} 


\section{Introdução: Schleiermacher como filósofo}

Nas pesquisas sobre a filosofia clássica alemã, além das fronteiras mais imediatas da língua germânica, não é recorrente encontrarmos estudos sobre Friedrich D. E. Schleiermacher (1768-1834). Pelo contrário, com respeito às expectativas que são geradas pelo assunto, menções à sua contribuição filosófica aparecem, quando muito, de maneira marginal, ou com o intuito de matizar polêmicas intelectuais do período: por exemplo, a propósito de elucidar as críticas de Georg W. F. Hegel (1770-1831) dirigidas contra o romantismo e a teologia do sentimento. Considerando especialmente a difusa recepção filosófica do pensamento de Schleiermacher, verificamos pelo menos duas razões principais que dificultaram o reconhecimento de seu legado filosófico (ARNDT, 2013, 17-18): em primeiro lugar, não restam dúvidas de que os efeitos mais incisivos de sua produção intelectual se fizeram notar, sobretudo, no campo da teologia protestante e nos estudos de religião. Porém, não se trata de dizer, simplesmente, que o sucesso teológico ofuscou o brilho filosófico. Infelizmente, os escritos filosóficos mais importantes não foram concluídos e preparados para a publicação, ao contrário de suas obras teológicas. Por este motivo, em segundo lugar, os efeitos de sua produção filosófica se restringiram basicamente às preleções universitárias, as quais só vieram a lume, fragmentária e paulatinamente, a partir de 1834, imediatamente após a sua morte ${ }^{2}$. Logo, por razões editorias, o acesso à letra de sua filosofia permaneceu durante muito tempo precário e insuficiente, e mesmo a preparação crítica contemporânea não é capaz de solucionar, de uma vez por todas, a inconclusividade de suas obras.

Mas a lacuna literária supramencionada não impediu que houvesse uma primeira recepção de suas ideias filosóficas. Só que ela ocorreu de maneira indireta por meio de sua atividade docente em Berlim e mediante o espólio de seu pensamento através de seus alunos - influências que se fizeram sentir, por exemplo, nos domínios da história da filosofia e da lógica ${ }^{3}$, assim como na teoria da ciência, interpretada à luz do neokantismo ${ }^{4}$. Contudo, os efeitos filosóficos se dissiparam paulatinamente em recepções isoladas, a serviço do desenvolvimento de disciplinas particulares - especialmente nos domínios da ética, da dialética, da hermenêutica e da pedagogia. De tal modo que não encontramos

\footnotetext{
${ }^{2}$ A primeira publicação das Obras Completas (sämmtliche Werke) ocorreu entre os anos de 1834 e 1864 , sob os cuidados de seus discípulos, cuja edição alcançou 31 volumes e foi agrupada em três seções: 1teologia, 2- prédicas e 3- filosofia. Mesmo se tratando do maior empreendimento editorial até aquele momento, ele reuniu apenas um conjunto limitado de escritos, preleções e cartas, deixando inauditos os manuscritos de juventude e privilegiando as edições finais das obras publicadas. Depois de várias tentativas fracassadas e publicação apenas de obras seletas - por exemplo, no período de 1910 a 1913 apareceu uma coletânea em quatro volumes Auswahl in vier Bänden - esta situação só se modificou a partir de 1972, com o projeto de organização e publicação sistemática da Edição Crítica das obras completas (Kritische Gesamtausgabe - KGA) - cujos volumes ainda continuam a ser publicados até hoje, possibilitando, para a pesquisa atual, tanto o resgate de suas contribuições filosóficas, quanto uma melhor apreciação de seu pensamento como um todo.

${ }^{3}$ Por exemplo, através de Friedrich Ueberweg (1826-1871) e de Friedrich Adolf Trendelenburg (18021872) - este último foi aluno de August Twesten (1789-1876), discípulo de Schleiermacher.

${ }^{4}$ Por exemplo, através de Christoph Sigwart (1830-1904).
} 
facilmente pesquisas que se dediquem a oferecer sínteses sistemáticas sobre o conjunto de sua produção filosófica ${ }^{5}$.

Em virtude das lacunas literárias e da recepção fragmentada de seu pensamento, torna-se compreensível porque até hoje foi difícil encontrar consenso sobre o lugar de direito de Schleiermacher na história da filosofia: os manuais tradicionais ou o ignoraram completamente, ou o limitam a filósofo da religião e da fé, dado que neste terreno não restam dúvidas de seu protagonismo. Exceção digna de nota valeu para a recepção gradual de seus manuscritos sobre hermenêutica, provavelmente a única disciplina com repercussão mais abrangente e que exerceu impacto na filosofia do século $\mathrm{XX}^{6}$, inclusive no contexto da pesquisa brasileira através dos estudos e traduções de Celso Reni Braida ${ }^{7}$ e Aloísio Ruedell ${ }^{8}$. No entanto, considerando especialmente a pesquisa nacional, enfrentamos ainda o dilema da ausência de traduções das principais obras e de seus comentadores. E isso não diz respeito apenas aos escritos filosóficos, já que contamos apenas com a tradução, academicamente insuficiente, de Daniel Costa do escrito teológico Über die Religion"; e carecemos ainda da tradução da Glaubenslehre, considerada a principal obra teológica protestante do século XIX.

Neste artigo visamos salientar as contribuições filosóficas de Schleiermacher no tocante à pesquisa atual acerca da filosofia clássica alemã. Primeiro, nos ocuparemos de uma breve discussão sobre o problema de seu lugar sistemático nas reconstruções tradicionais da história da filosofia, levando em conta importante estudiosos do período. Em seguida, a partir de uma breve análise de suas preleções universitárias sobre Dialética, buscaremos determinar o núcleo do seu conceito de filosofia enquanto arte do diálogo. Por fim, levantaremos questões hermenêuticas pertinentes à reconstrução históricofilosófica de Schleiermacher como um filósofo alemão clássico.

\section{Schleiermacher e a filosofia clássica alemã}

A partir de uma visada distanciada e genérica, poder-se-ia afirmar que as expressões filosofia clássica alemã e idealismo alemão sejam intercambiáveis, cuja fórmula afamada de Kant a Hegel acabou por se firmar como um período da história da filosofia. Porém, à medida que nos aproximamos destes conceitos e de sua gênese histórica, deparamo-nos com dificuldades no que concerne ao esclarecimento preciso dos qualificativos clássico e idealismo. Pois eles bem podem se referir a um "conceito de época” mais ou menos abrangente, como também podem remeter a um "conceito material" que diz respeito apenas à determinada corrente de pensamento dentro de um período filosófico específico (JAESCHKE, 2004, p. 296). Neste último caso, quanto

\footnotetext{
${ }^{5}$ Neste particular, dispomos basicamente das seguintes contribuições: ARNDT, 2013; PLEGER, 1988; SCHOLTZ, 1984; FISCHER, 2001; NOWAK, 2001; BRANDT, 1941.

${ }^{6}$ Principalmente através dos estudos de Hans-Georg Gadamer (1900-2002), Heinz Kimmerle (1930-2016) e Manfred Frank (1945-).

${ }^{7}$ SCHLEIERMACHER, 1999.

${ }^{8}$ SCHLEIERMACHER, 2005.

${ }^{9}$ SCHLEIERMACHER, 2000.
} 
maior sua determinação material, maior é a exclusão de determinados autores, ainda que situados dentro de um mesmo contorno histórico. Por esta razão, o conceito de idealismo tende a ser mais problemático: por um lado, ele é aplicável apenas a uma parcela de filósofos e, portanto, impróprio como conceito de época; por outro lado, tratou-se de um produto neokantiano tardio, que sequer corresponde ao programa filosófico de seus principais protagonistas, já que todos eles propunham a "superaração das alternativas entre idealismo e realismo" (ARNDT, 2013, p. 21).

Seja como for, se entendemos a filosofia clássica alemã como um conceito de época - menos problemático do que o conceito de idealismo -, nem por isso ele está imune à arbitrariedade dos recortes temporais e dos preconceitos de escola. Já a própria expressão remonta ao opúsculo de Friedrich Engels, Ludwig Feuerbach und der Ausgang der klassischen deutschen Philosophie (1888). Como bem destacou Erst-Otto Onnasch (2011, p. 110), clássico aqui significa o período entre Kant (1724-1804) e Feuerbach (1804-1872) - de tal modo que o materialismo feuerbachiano consistiria na superação crítica da filosofia hegeliana e, portanto, estágio prévio do socialismo científico. Onnasch salienta dois problemas fundamentais de tal concepção: primeiramente, não temos aqui um conceito neutro, a propósito da história e filosofia alemãs, mas valorativo - não pertence a esta herança a filosofia burguesa e liberal, como, por exemplo, a dos românticos; adicionalmente, defende-se aqui explicitamente uma linearidade históricofilosófica partindo de Kant e obtendo sua consumação com Hegel e Feuerbach (ONNASCH, 2011, p. 110-111).

Com o intuito de superar estas limitações supramencionadas, assim como para valer como um conceito de época da história da filosofia, Walter Jaeschke argumenta a favor da terminologia filosofia clássica alemã, compreendendo-a, porém, como uma unidade de pensamento que "não se encontra na concordância de principio entre os filosofantes, mas na complexa ligação entre acordo e desacordo” (JAESCHKE, 2004, p. 297). Desta forma, esta nova compreensão se distancia da perspectiva de Engels, para quem Schleiermacher não tem lugar entre os clássicos, conquanto expoente do romantismo e da filosofia burguesa. Ademais, esta nova orientação não só recupera autores importantes do período, frequentemente marginalizados, mas também amplia o horizonte interpretativo que tendiam a cristalizá-los em etapas intermediárias do desenvolvimento dialético que culminaria em Hegel.

Principalmente a partir dos estudos seminais sobre o idealismo de Dieter Henrich, a partir da década de setenta do século passado, a pesquisa sobre filosofia clássica alemã abandonou um esquema predominantemente lógico-dialético, com Hegel em seu auge, e passou a investigar cada vez mais as produções filosófica entre Kant e Hegel, reavaliando-as como contribuições próprias e com direções multivariadas (HENRICH, 2003). Por conseguinte, podemos traçar linhas de continuidades e descontinuidades entre diversos autores, que forjaram, a cada vez, soluções próprias e até irredutíveis, pois o que se leva em conta é uma constelação de discussões e de problemas compartilhados ${ }^{10}$. Com efeito, a partir do momento em que Schleiermacher é revitalizado, mais que nunca devemos questionar o significado sistemático de sua reivindicação como filósofo clássico,

\footnotetext{
${ }^{10}$ D. Henrich (2003, p. 279 et seq.) recupera, por exemplo, a importância de Friedrich Hölderlin (17701843), mas, infelizmente, não se dedicou ao pensamento de Schleiermacher.
} 
ou seja, devemos esclarecer sua posição sistemática dentro do período da filosofia clássica alemã.

Não é de hoje que influentes historiadores da filosofia se debruçam sobre o intenso movimento intelectual produzido na Alemanha nos fins do século XVIII e primeira metade do século XIX. Do ponto de vista histórico e sistemático, destacou-se, na primeira metade do século XX, a obra Von Kant bis Hegel de Richard Kroner, publicada em dois volumes, respectivamente, nos anos de 1921 e 1924. Para este autor, no essencial, o desenvolvimento do idealismo alemão teria início com a publicação da Crítica da Razão Pura de Kant (1781), e seu fim - não só cronológico, mas também escatológico - com a publicação da Filosofia do Direito de Hegel (1821) (KRONER, 1921, p. 1). No segundo volume desta obra, no contexto da passagem da filosofia da natureza para a filosofia do espírito, Kroner dedica uma breve seção a Schleiermacher enquanto uma modalidade do idealismo estético, apoiando-se no escrito romântico de 1799, Über die Religion. Todavia, o problema desta interpretação se deve à circunscrição da filosofia schleiermacheriana ao primeiro romantismo (Früromantik), razão pela qual se apoia somente no escrito publicado durante sua colaboração no círculo romântico. Só que esta fonte literária não só é insuficiente para extrair todo o conteúdo filosófico de seu pensamento, como também inapropriada, dado que se tratava de um escrito, a rigor, de teologia filosófica (OLIVEIRA, 2016).

Por sua vez, em sua obra Die Philosophie des deutschen Idealismus, publicada também em dois volumes (1923, 1929), Nicolai Hartmann acompanha o lema de Kant a Hegel de Kroner, mas salienta o fato de que, independentemente das diferenças das várias tendências, dois polos atuavam em conjunto, a filosofia kantiana e o empenho por um sistema de filosofia. Nesta obra, Schleiermacher recebeu uma avaliação em parte mais justa, pois Hartmann leva em consideração não só sua filosofia da religião, mas também sua concepção de dialética e de ética. Do ponto de vista sistemático, nosso autor é apresentado novamente como romântico, muito embora se diferencie de F. Schlegel (1772-1829) e de Novalis (1772-1801), pois estes últimos não tinham pretensão de elaborar um sistema, ainda que inacabado e aberto. Porém, no entender de Hartmann, uma vez mais pesa em Schleiermacher o fato de que fosse antes teólogo do que filósofo, de tal modo que sua filosofia consistia, sobretudo, em filosofia da religião (HARTMANN, 1960, 199 et seq.). De ser assim, a dialética e a ética foram interpretadas à luz da concepção religiosa de fundo, pois nela estaria o centro de suas intuições filosóficas. Avaliação que não só é injusta - a julgar pela distinção que o próprio Schleiermacher busca realizar, no interior do seu sistema, entre as tarefas da filosofia e da teologia; mas, além disso, parece-nos uma crítica unilateral, visto que não vemos impedimento de generalizá-la também para os programas de Schelling ou de Hegel, e isso para dizer o mínimo.

O principal manual de história da filosofia mais recente a perseguir o desenvolvimento filosófico de nosso autor consiste na obra escrita a quatro mãos de Walter Jaeschke e Andreas Arndt (2012, pp. 254-305), Die Klassische Deutsche Philosophie nach Kant (2012). Os autores descrevem a filosofia pós-kantiana como o período situado entre os anos de 1785 e 1845, que se estende, do ponto de vista político, desde os anos imediatamente antes e pós-revolução francesa até o fim do Vormärz. Como principais características, eles destacam a filosofia transcendental de Kant e a ascensão do Espinosismo na Alemannha, este último responsável pelas controvérsias envolvendo 
as disputas sobre o panteísmo, o ateísmo e o teísmo (JAESCHKE; ARDNT, 2012, p. 2426). Do ponto de vista sistemático, Schleiermacher é situado, uma vez mais, no âmbito do movimento Früromantik e de suas transformações, de modo similar ao tratamento dispensado por N. Hartmann, embora sem o esquema mais rígido do desdobramento que desembocaria em Hegel, deixando espaço, por exemplo, para a obra tardia de Fichte e de Schelling.

Segundo Jaeschke e Arndt, a decisão sobre o lugar de Schleiermacher no desenvolvimento da filosofia clássica alemã dependeria da resposta à questão proposta por Michael Theunissen (1992), a saber: se Schleiermacher encaminhou, dentro do idealismo, um pensar pós-idealista, ou se ele pode ser visto como um dos seus protagonistas que forneceu uma forma sistemática para a filosofia do romantismo inicial (JAESCHKE, ARNDT, 2012, p. 259). Os autores defenderam a segunda alternativa, já que Schleiermacher propõe efetivamente um sistema. Mas, junto com os românticos, tratar-se-ia de um sistema inconcluso e permanentemente em devir: um work in progress, cujo fundamento e fim não seriam, eles próprios, objetos de um saber.

Com efeito, a nosso ver, o aspecto que permanece passível de objeção é o de tributar, fundamentalmente, a filosofia schleiermacheriana ao movimento romântico inicial da virada do século XVIII para o século XIX (1797 até 1802). Ainda mais se consideramos sua atividade intelectual posterior a 1802, principalmente nos anos de docência em Berlim a partir de 1810, quando efetivamente desenvolveu sua compreensão sistemática da filosofia. Ora, compreendê-lo como um filósofo do primeiro romantismo tende a minimizar seu amadurecimento intelectual na obra tardia. A fim de aprofundar justamente este debate, buscaremos expor, a seguir, parte deste desenvolvimento tardio.

\section{Preleções universitárias sobre Dialética (1811-1831)}

Schleiermacher lecionava teologia na então Universidade de Berlim desde o ano de sua fundação, em outono de 1810, mas como membro da Königlich Preussischen Akademie der Wissenschaften, era-lhe permito lecionar também na faculdade de filosofia. Dialektik foi o rótulo que reuniu o espólio destas preleções filosóficas ministradas durante o período de 1811 até $1831^{11}$. Trata-se de uma coletânea de manuscritos, alguns bem estruturados e basicamente completos, outros bastante fragmentados. O caráter incompleto dos escritos e suas diferentes fontes de transmissão dificultaram o estabelecimento de um texto padrão, sem contar que eles pressupunham, na prática, esclarecimentos orais. Ainda assim, não obstante os obstáculos exegéticos de uma obra inconclusa, podemos derivar dela sua estrutura formal e suas principais teses.

O fio condutor inicial que nos permite um acesso a estes escritos repousa na compreensão da tarefa e da finalidade destas preleções. Os cursos de Dialética de Schleiermacher tinham a função de prolegômenos para sua filosofia, assinalando também o empenho sistemático de formulação e de execução de seu programa filosófico. Factualmente, as preleções deveriam contrabalançar a influência de Johann Gottlieb Fichte (1762-1814) - então professor de filosofia da Universidade de Berlim - de modo

11 Schleiermacher ministrou esta disciplina por seis vezes, a saber: no semestre de verão de 1811, no semestre de inverno de 1814/15, no semestre de inverno de 1818/19, no semestre de verão de 1822, no semestre de verão de 1828 e, por fim, no semestre de verão de 1831. 
que elas se propunham como solução alternativa à Wissenschaftslehre. O propósito de Schleiermacher em apresentar sua própria Doutrina da Ciência se deixa comprovar, por exemplo, num escrito sobre ética do ano de 1803, Kritik der Sittenlehre, onde emprega a terminologia fichteana enquanto uma "ciência dos fundamentos e do nexo sistemático de todas as ciências” (SCHLEIERMACHER, 2002b, p. 48). Em síntese, tratar-se-ia de uma teoria geral do saber que implica, ao mesmo tempo, uma discussão transcendental da fundamentação última do conhecimento; mas, diferentemente de Fichte, ela não poderia ser deduzida de maneira puramente a priori, ou seja, independentemente das ciências reais.

Contudo, o termo Doutrina da Ciência é substituído pela categoria Dialética a partir de $1810^{12}$. Não sabemos ao certo o momento decisivo em que Schleiermacher optou pela alteração do título da disciplina, mas em Brouillon zur Ethik (1805/06) ele alude a

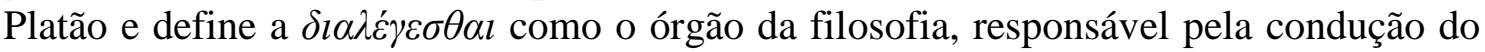
diálogo no campo do saber (SCHLEIERMACHER, 1913, p. 164). Existem dois indícios plausíveis para se compreender esta mudança. $\mathrm{O}$ primeiro tem a ver com o projeto de tradução da obra completa de Platão, iniciado em 1804, e que o levou a aprofundar os estudos da obra platônica ${ }^{13}$. Neste particular, o vínculo com F. Schlegel é fator a ser considerado, sem contar o fato de que este já havia desenvolvido uma compreensão positiva de dialética pelo menos desde $1796^{14}$. O segundo indício está no contato mais próximo com a filosofia de Schelling a partir de 1804, autor que desenvolveu uma compreensão positiva da arte dialética nas Preleções sobre o método do estudo acadêmico (1803) - muito embora não se deixe comprovar, cabalmente, a admissão consciente de Schleiermacher deste conceito schellingiano.

Além disso, devemos ressaltar que não há indicação, quer textual quer biográfica, de que Hegel, com a publicação da Fenomenologia do Espírito (1807), tenha exercido influência na concepção terminológica de Schleiermacher. Até porque, o último só teria adquirido este escrito hegeliano a partir de 1816, juntamente com a Ciência da Lógica (1812/13/16); ao passo que o escrito Diferenças entre os sistemas filosóficos de Fichte e de Schelling (1801), que Schleiermacher provavelmente conheceu, não faz uso da terminologia dialética ${ }^{15}$. Portanto, em síntese, podemos afirmar o seguinte: a partir de 1810 houve, efetivamente, uma convergência entre o projeto de uma Doutrina da Ciência (1803) - termo então abandonado - e uma compreensão positiva de $\delta \imath \alpha \lambda \varepsilon ́ \gamma \varepsilon \sigma \theta \alpha \iota$ (1805/06), de tal modo que sua unificação concretizou-se nas preleções sobre Dialética. A conquista gradual do conceito de dialética correspondeu ao próprio esforço de

\footnotetext{
${ }^{12}$ Conforme carta de Schleiermacher enviada a Joachim Christian Gass (1766-1831), na qual relata seu intento de expor uma disciplina intitulada Dialética, e que esta ideia ele trazia consigo já há algum tempo, embora não relate desde quando (SCHLEIERMACHER, 2002a, p. VIII).

${ }^{13} \mathrm{O}$ projeto de tradução de Platão deveria ser realizado, a princípio, conjuntamente com F. Schlegel, mas Schleiermacher continuou o projeto sozinho.

${ }^{14}$ A. Arndt (2013, p. 194 et seq.) defende a tese de que, para Schleiermacher, mas também para Schelling, foi fundamental o contato com Friedrich Schlegel que possuía já desde muito cedo - pelo menos desde 1796, uma compreensão positiva de dialética como a autêntica arte - na contramão da concepção negativa de Kant de dialética como aparência.

${ }^{15}$ Cf. SHLEIERMACHER, 2002a, p. XXIII-XXIV.
} 
Schleiermacher em definir a tarefa do filosofar e suas condições, cuja especificidade será nosso objeto de exame adiante.

\section{Filosofia como arte do diálogo ${ }^{16}$}

Dialética consiste numa investigação que contém os "princípios da arte do filosofar”, ou a "arte de conduzir um diálogo", ou ainda, os "princípios para a condução de diálogo, em conformidade com a arte, no âmbito do pensar puro", segundo as definições fornecidas, respectivamente, nos manuscritos de 1814/15 e 1822, bem como na Versão Final da Introdução ${ }^{17}$ de 1833 (SCHLEIERMACHER, 2002a, p. 77; 219; 393). A compreensão da filosofia como dialética tinha o intuito de corrigir os impulsos especulativos de seus contemporâneos que pretendiam reivindicar, para a filosofia primeira, um ponto de partida incondicionado, ou até mesmo uma Ciência do Absoluto lição que nosso autor julgava ter aprendido com Platão, conforme atesta uma passagem do Caderno de Notas de 1811: “O que Platão diz do á $\gamma \alpha \theta$ óv (...) isso vale para o Absoluto. A ciência e a verdade não são o Absoluto, mas provém dele” (SCHLEIERMACHER, 2002a, p. 8; 224). Posto de outra maneira, para nosso autor, o conceito de Absoluto, designado também de fundamento transcendental, comporta-se como um conceito-limite a propósito da fundamentação última do conhecimento. Mas ele não consiste em objeto de um saber ou ciência. Neste particular, Schleiermacher se entende como um herdeiro de Kant e da Transzendental-Philosophie, porém, ele rejeita o pensamento especulativo, por exemplo, de Fichte e de Schelling, por considerá-los resultado da sobreposição do princípio filosófico e do princípio cristão - ou seja, a reivindicação de uma Ciência do Absoluto teria motivação histórica, em virtude da experiência religiosa cristã (SCHLEIERMACHER, 2002a, p. 80; 211). Em síntese, a Dialética se opõe a toda e qualquer corrente filosófica que, de uma ou outra maneira, estorva os limites entre saber filosófico e dimensão religiosa.

Para compreendermos sua proposta, devemos nos deter, especialmente, nos conceitos de pensar puro e de condução de diálogo. Na sua acepção mais ampla, o ato de pensar é entendido como uma função espiritual, ou seja, como uma capacidade de representação; na sua acepção mais estrita, o pensamento é toda e qualquer representação expressa por meio da linguagem. Schleiermacher distingue três tipos de atos do pensamento: o pensar prático (geschäftlich), o pensar artístico (künstlerisch) e o pensar puro (rein). O primeiro está relacionado com o agir, caracteriza-se pelos elementos de autodeterminação e de finalidade, do domínio do homem sobre a natureza e sobre os outros homens. O segundo tipo constitui-se de atos momentâneos de pensamento, vinculados a percepções e sensações internas, livres de uma finalidade prática imediata. O terceiro tipo de pensar se assemelha ao segundo tipo, mas ele se dirige especialmente à esfera do conhecimento e da ciência, portanto, detém pretensões de universalidade. De ser assim, o pensar prático atua em função de uma finalidade externa, ao passo que o

\footnotetext{
${ }^{16}$ Para uma exposição melhor detalhada do que se segue, veja nossa contribuição OLIVEIRA, 2015, p. 69 et seq.

${ }^{17}$ Texto introdutório com vistas à publicação da Dialética, mas que foi interrompido abruptamente com a morte de Schleiermacher em 1834.
} 
pensar puro e artístico têm em comum o fato de que atuam em razão do próprio pensar (SCHLEIERMACHER, 2002a, p. 393-395).

Assim, o pensar artístico e o pensar puro possuem um caráter autorreferencial pelo fato de que se trata de um ato de pensamento que se relaciona com sua própria atividade pensante. Em virtude disso, podemos atribuir-lhes uma modalidade específica de diálogo. O pensar artístico consistiria num tipo de diálogo livre; ao passo que o pensar puro seria responsável pela condução de diálogo (Gesprächführung). Por conseguinte, condução de diálogo, segundo Schleiermacher, não significa uma conversação entre pares, mas diz respeito ao diálogo de um ser pensante consigo mesmo, tratando-se, rigorosamente, de um monólogo (Selbstgespräch) do espírito (SCHLEIERMACHER, 2002a, p. 397). Além disso, como se disse, todo pensar também implica linguagem. Por esta razão, segundo Schleiermacher (2002a, p. 401), o monólogo se efetiva sempre no interior de um círculo linguístico (Sprachkreiss). A correlação intrínseca entre pensamento e linguagem foi estabelecida pela primeira vez em Brouillon zur Ethik (1805-06), quando se ressaltou que o diálogo ( $\delta \imath \alpha \lambda \varepsilon ́ \gamma \varepsilon \sigma \theta \alpha l$ ), que almeja um saber idêntico (universal), somente se comunica por meio da individualidade ou particularidade do discurso (Reden) (SCHLEIERMACHER, 1913, p. 164) ${ }^{18}$. Isso significa dizer que a dimensão universal do conhecimento é condicionada pelas determinações individuais e históricas do círculo linguístico, de tal modo que o saber jamais alcança uma universalização absoluta ${ }^{19}$. No entanto, deve-se cuidar do equívoco de compreender a condução de diálogo como uma comunicação dialógica ou processo de entendimento de discursos. Com efeito, a linguagem pertence à esfera de comunicação dos resultados, mas não é suficiente para explicar o fundamento de sua própria produção.

Uma vez esclarecidos os conceitos de condução de diálogo e de pensar puro, podemos avançar para a determinação da filosofia enquanto arte do diálogo. A tarefa filosófica fundamental, para Schleiermacher, consiste na busca por um saber idêntico, universal, a fim de superar as diferenças das representações do pensamento que, efetivamente, atualizam-se histórica e linguisticamente. Porém, o saber idêntico permanece, sempre e a cada vez, provisório e passível de aperfeiçoamento, dado que não pode suprimir, de uma vez por todas, as particularidades linguístico-culturais. Para nosso autor, no domínio do conhecimento, a busca por um saber idêntico surge por causa da necessidade de superação da dúvida e do conflito (Streit) - em outras palavras, uma disciplina como a Dialética é requisitada justamente em virtude da existência da divergência; de tal modo que sua exigência é tanto maior, quanto maior a controvérsia. Ora, a doutrina da arte não deve estabelecer um método específico para solucionar este ou aquele conflito em particular, mas precisa estabelecer apenas os princípios em sua

\footnotetext{
18 No manuscrito de 1822, Schleiermacher referia-se também à conexão intrínseca entre pensamento e discurso, na medida em que o pensar universal comunica-se por meio da individualidade do discurso (SCHLEIERMACHER, 2002a, p. 230).

${ }^{19} \mathrm{Em}$ virtude deste laço estreito entre as formas do pensamento e suas estruturas linguísticas, intentou-se, na literatura especializada, correlacionar essencialmente os escritos sobre Dialética com os escritos sobre Hermenêutica. Decerto existem pontos de contato entre ambos, porém, houve uma sobrevalorização da Hermenêutica para a determinação da filosofia de Schleiermacher, embora seu uso estivesse vinculado especialmente com os estudos teológicos, razão pela qual os escritos sobre Hermenêutica foram publicados, pela primeira vez, na seção de teologia, por causa de sua aplicação ao Novo Testamento (Hermeneutik und Kritik mit besonderer Beziehung auf das Neue Testament) (SCHLEIERMACHER, 1834-64).
} 
universalidade, com o intuito de fomentar a unidade no contexto do pensar cindido, pois sua finalidade consiste na superação das diferenças no âmbito do pensar puro.

No entanto, a arte dialética não surge somente em razão dos conflitos das representações, mas ela pressupõe igualmente um impulso originário ao saber, que Schleiermacher designa de querer-saber (Wissenswollen), ou ainda, de amor ao saber (Wissensliebe) (SCHLEIERMACHER, 2002a, p. 373). Aproveitando-se da atmosfera platônica que envolve tal definição, o amor ao saber ${ }^{20}$ consiste, por um lado, numa dimensão pré-científica responsável pela promoção do saber, mas, por outro lado, o amor ao saber acentua a incompletude do conhecimento, razão pela qual se carece da arte dialética. Neste particular, argumentando contra sistemas de filosofia que reivindicam um princípio incondicionado ou absoluto como ponto de partida, Schleiermacher assevera que não existe ponto de partida livre do (ou anterior ao) estado de conflito. Nem mesmo o querer-saber é um ponto de partida inicial, pois já sempre nos achamos sob seu influxo e, além disso, o querer-saber não determina o conteúdo de um conhecimento, mas apenas instiga o espírito para seu autoconhecimento.

Considerando a compreensão geral da arte do diálogo analisada até aqui, podemos retirar pelo menos três conclusões gerais sobre o projeto filosófico que lhe é inerente. Em primeiro lugar, se Schleiermacher se vincula à discussão transcendental kantiana, ele busca superar, porém, o sentido pejorativo da Dialética como lógica das aparências. A Dialética transcendental kantiana implicava num uso restritivo dos conceitos da razão pura (Deus, alma e mundo), enquanto princípios regulativos que nada dizem acerca do conteúdo do conhecimento, mas apenas das condições formais da concordância como o intelecto, de tal modo que não ampliariam ou estenderiam o conhecimento. Contudo, Schleiermacher revaloriza a Dialética como a arte filosófica par excellence, visto que ela, embora não seja desconectada das ciências reais, expõe os princípios e o sistema do saber.

Em segundo lugar, a centralidade do conceito de arte filosófica, para a esfera do pensar puro, no lugar do conceito de ciência filosófica, revela a tese de fundo antiespeculativa de um saber que está permanentemente em devir. A arte filosófica busca a efetivação do saber real, mas não a efetivação de um saber sobre o Absoluto. Rigorosamente considerada, a filosofia teórica só se realizaria plenamente, como ciência, no fim de sua jornada e no momento da completude de todos os saberes. Neste particular, o desiderato de uma aproximação recíproca entre arte e ciência, indica a concordância de Schleiermacher (2002a, p. 77, 79) com o projeto romântico de F. Schlegel de uma Symphilosophie, a saber: a tese de que arte e ciência deveriam convergir, mas apena no fim, e cuja tarefa seria a de uma aproximação infinita (FRANK, 1997). Mas este projeto também se conecta, sem dúvida, com Schelling, porque Schleiermacher defende um fundamento originário (Urgrung) como ponto de indiferença entre os elementos ideal e real, ainda que este saber extrapole a possibilidade objetiva do filosofar, se houver a pretensão de estendê-lo para além dos limites do pensar puro ou transcendental.

Em terceiro e último lugar, ainda que assumíssemos o argumento de que o projeto filosófico de Schleiermacher permanecesse, fundamentalmente, romântico, ele precisaria

\footnotetext{
${ }^{20}$ Ulrich Barth indica que essa noção seria uma reformulação crítica do conceito de ideia retirado do Simpósio de Platão, ou seja, a filosofia tem por "tarefa conduzir ao conceito aquela práxis do saber préreflexivo"; ademais, Barth salienta o fato de que a Dialética, enquanto doutrina da arte, pretendia fazer frente à hipertrofia da formação filosófica de sistemas da razão da época moderna (BARTH, 2004, p. 356).
} 
ser matizado - justamente porque nosso autor assume uma posição intermediária ${ }^{21}$ : posição que reúne, simultaneamente, argumentos defendidos tanto por Schlegel quanto por Schelling. Além disso, não se pode ignorar sua leitura e apropriação singulares de Platão. Ora, se o estudo dos pontos em comum e das divergências entre os filósofos do período clássico alemão nos oferecem oportunidades de esclarecer, respectivamente, os projetos filosóficos de cada expoente do período. Nem por isso devemos reduzi-los um ao outro, tática que pouco contribui para uma compreensão mais profunda dos problemas em questão. Talvez fosse mais adequado reconhecer o desenvolvimento filosófico original e próprio de Schleiermacher, cuja dívida permanente ao movimento Frühromantik bem pode ocultar sua produção filosófica madura; produção que, inclusive, continuou a ser constantemente corrigida e ampliada a cada nova exposição da Dialética.

\section{Considerações finais}

Procuramos expor brevemente aspectos filosóficos do pensamento de Schleiermacher, questionando especialmente seu lugar sistemático no contexto dos estudos de filosofia clássica alemã. A pesquisa contemporânea tem modificado o panorama dos esquemas tradicionais de interpretação, sobretudo mediante o acesso crítico às obras completas de filósofos até então marginalizados, cuja importância se perdeu no decurso da história dos efeitos e da historiografia convencional. O refinamento das complexas inter-relações entre os autores descortinam um conjunto de problemas e de soluções bem mais diversificados do que a leitura padrão julgava existir, e isso exige rearranjos na organização geral de nossa compreensão do período. É verdade que o trabalho da história da filosofia sempre traz consigo um caráter mais ou menos esquemático. Porém, não é necessário enrijecer os autores, ou reduzi-los a clichês interpretativos.

Apresentamos sinteticamente a compreensão de filosofia elaborada por Schleiermacher e buscamos contextualizá-la dentro de um conjunto de problemas compartilhados pelos filósofos de seu tempo, sobretudo em relação à fundamentação da filosofia e de suas pretensões cognitivas. Naturalmente, não foi possível oferecer, nesta modesta contribuição, uma avaliação global de sua filosofia, nem mesmo avançamos nas discussões filosófico-transcendentais da Dialética. Pretendíamos apenas examinar o cerne do seu conceito de filosofia, assim como sublinhamos as deficiências de certas abordagens recorrentes no estudo de Schleiermacher no contexto da filosofia clássica alemã.

Com respeito à questão mencionada no início deste artigo, se a filosofia schleiermacheriana encaminhou, dentro do idealismo, um pensamento pós-idealista, ou se ela é um modelo de romantismo sistematizado, deveríamos atentar para o seguinte

${ }^{21}$ Já se argumentou também que Schleiermacher estaria a um passo entre Kant e o sistema idealista especulativo, na medida em que restringe, de um lado, a razão especulativa (como Kant); mas, de outro lado, buscaria superar (como o idealismo em geral) a solução dualista kantiana para as antinomias no uso especulativo da razão (ARNDT, 1993, p. 110). 
problema hermenêutico: independentemente da resposta a esta questão, parece-nos que o pressuposto de fundo é o de que Schleiermacher não desfrutasse de um pensamento consistente por si mesmo. Ou ele, sendo um idealista (modesto), abriu caminho para filosofias pós-idealistas; ou desenvolveu e organizou as intuições românticas precedentes, porque demasiado aforísticas, mas cuja liderança espiritual pertencia especialmente a $\mathrm{F}$. Schlegel. Com efeito, seja qual for a solução encontrada, ficamos com a impressão de que seu lugar filosófico fosse extemporâneo: pois pertencente ou a um passado romântico (que já foi), ou a um futuro pós-idealista (que ainda virá). Mas deveríamos nos perguntar o seguinte: dispomos realmente apenas destes dois caminhos possíveis para a solução deste problema de interpretação? A resposta a esta questão condiciona evidentemente o lugar de Schleiermacher no conjunto da filosofia clássica alemã.

\section{Referências}

ARNDT, A. Gefühl und Reflexion: Schleiermachers Stellung zur Transzendentalphilosophie im Kontext der Zeitgenössischen Kritik an Kant und Fichte. In: JAESCHKE, W. (Org.). Transzendentalphilosophie und Spekulation (2 v.). Hamburg: Meiner,1993, pp. 105-126.

ARNDT, Andreas. Schleiermacher als Philosoph. Berlin: Walter de Gruyter, 2013.

BARTH, Ulrich. Aufgeklärter Protestantismus. Tübingen: Mohr Siebeck, 2004.

BRANDT, Richard B. The Philosophy of Schleiermacher: the Development of his Theory of Scientific and Religious Knowledge. New York: Happers and Brothers Publishers, 1941.

FISCHER, Hermann. Friedrich Schleiermacher. München: Beck, 2001.

FRANK, Manfred. Unendliche Annäherung: Die Anfänge der philosophischen Frühromantik. Frankfurt am Main 1997.

HARTMANN, Nicolai. Die Philosophie des deutschen Idealismus. Berlin: Walter de Gruyter, 1960.

HENRICH, Dieter. Betwenn Kant and Hegel: lectures on German idealism. Cambridge; Massachusetts; London: Harvard University Press, 2003.

JAESCHKE, Walter; ARNDT, Andreas. Die klassische deutsche Philosophie nach Kant: Sisteme der reinen Vernunft und ihre Kritik. München: Beck, 2012.

Sobre o conceito de filosofia alemã clássica. Trad. Joãosinho Beckenkamp. In: Dissertatio (19-20). 2004, p. 295-312. 
KRONER, Richard. Von Kant bis Hegel (2 v.). Tübingen: JCB Mohr (P. Siebeck), 1921-1924.

NOWAK, Kurt. Schleiermacher: Leben, Werk und Wirkung. Göttingen: Vandenhoeck \& Ruprecht, 2001.

OLIVEIRA, Davison Schaeffer de: Filosofia da Religião e Ciência da Religião: breves incursões em diálogo com Schleiermacher. In: Horizonte: Revista de Estudos de Teologia e Ciências da Religião, 2016, p. 1565-1588.

. Filosofia e Teologia em Friedrich Schleiermacher: a teoria do sentimento como ponto de inflexão dos princípios da Dialética e da Dogmática. 2015. Tese (Doutorado em Ciência da Religião) - Instituto de Ciências Humanas, Universidade Federal de Juiz de Fora, Juiz de Fora.

ONNASCH, Erst-Otto. Von Kant zu Hegel: Oder: Was heißt klassische deutsche Philosophie? In: WIEGERLING, Klaus; LENSKI, Wolfgang. Wissenschaft und Natur: Studien zur Aktualität der Philosophiegeschichte (Festschrift fur Wolfgang Neuser zum 60. Geburtstag). Nordhausen: Traugott Bautz, 2011, p. 109-123.

PLEGER, Wolfgang H. Schleiermachers Philosophie. Berlin: Walter de Gruyter, 1988.

SCHLEIERMACHER, Friedrich. Entwürfe zu einem System der Sittenlehre: nach den Handschriften und eingeleitet von Otto Braun. Leipzig: Felix Meiner, 1913.

. Grundlinien einer Kritik der bisherigen Sittenlehre. In: Schriften aus der Stolper Zeit (1802-1804). Berlin; New York: Hamburg: Walter de Gruyter, 2002b.

. Hermenêutica: arte e técnica da interpretação. Trad. de Celso Reni Braida. Petrópolis: Vozes, 1999.

. Hermenêutica e Crítica: com um anexo de textos de Schleiermacher sobre filosofia da linguagem. Ijuí: Unijuí, 2005.

. Sämmtliche Werke (Abt. 1, v. 7). Berlin: Georg Reimer, 1834-64.

Sobre a religião: discursos a seus menosprezadores eruditos. Trad. Daniel Costa. São Paulo: Novo Século, 2000.

Vorlesungen über die Dialektik. Berlin; New York: Walter de Gruyter, 2002a. SCHOLTZ, Gunter. Die Philosophie Schleiermachers. Darmstadt: Wissenschaftliche Buchgesellschaft, 1984. 